\title{
Distribution and partitioning of trace element in the cellular compartments of marine phytoplankton exposed to metals
}

\author{
Godinho, R.M. ${ }^{* * *}$, Cabrita, T.**, Alves, L. , Pinheiro, T.
}

*Instituto de Biociências e Bioengenharia (IBB), Instituto Superior Técnico, Universidade de Lisboa, Av. Rovisco Pais 1, Lisboa, PORTUGAL.

*** Instituto Português do Mar e da Atmosfera (IPMA), Av. de Brasília, Lisboa, PORTUGAL.

\section{Email: rmgodinho@yahoo.com}

Diatoms are efficient scavengers of trace elements, including pollutants, playing a key role in their distribution and cycling in aquatic ecosystems. Coscinodiscus is a pollution tolerant genus that often dominates the phytoplankton community in coastal zones.

The main objective of the present study was to evaluate metal content and compartmentalization changes in whole cells of diatom Coscinodiscus eccentricus exposed to different metal loads, in order to use this alga as biomonitor of metal pollution.

Accurate descriptions of intracellular elemental distributions can provide diverse information about the physiological and accumulation mechanisms [1]. However, the determination of intracellular elemental distributions in isolated whole cells is challenging. Nuclear Microprobe is a powerful tool for the determination of multi-elemental distributions in tissues and cells [2,3]. Using a combination of three techniques, PIXE (Particle Induced X-ray Emission), RBS (Rutherford Backscattering Spectroscopy) and STIM (Scanning Transmission Ion Microscopy), real-time morphological images and elemental mapping can be produced with relatively good lateral resolution (typically 1-3 $\mu \mathrm{m}$ ) and excellent sensitivity for metal quantification down to the parts per million levels. Axenic cultures of Coscinodiscus eccentricus isolated from Tagus estuary and maintained in $\mathrm{f} / 2$ media were subjected to exposure experiments by addition of the trace metals $\mathrm{Ni}\left(\mathrm{NiCl}_{2}\right), \mathrm{Cu}\left(\mathrm{CuSO}_{4} \cdot 5 \mathrm{H}_{2} \mathrm{O}\right)$ and $\mathrm{Zn}\left(\right.$ as $\left.\mathrm{ZnSO}_{4} \cdot 7 \mathrm{H}_{2} \mathrm{O}\right)$ to obtain final concentrations of $2 \mu \mathrm{g}$ $\mathrm{L}^{-1}, 3 \mu \mathrm{g} \mathrm{L}^{-1}$ and $14 \mu \mathrm{g} \mathrm{L}^{-1}$, respectively, reflecting the highest concentrations found in contaminated areas of the Tagus estuary [4].

Figure 1 shows images of non-exposed (upper plate) and exposed (lower plate) cells. The STIM image gives information about density variations of the sample. This information together with the mapping of the major elements, such as $\mathrm{C}$ and Si using RBS, and minor elements, such as S and K using PIXE, enabled to identify the presence of intracellular compartments. The homogeneous Si distribution evidenced the cell wall, whereas the high $\mathrm{C}$ and $\mathrm{K}$ contents in the periphery of the cell are consistent with the presence of the parietal cytoplasm, which also associated $\mathrm{Mn}$ and Fe. The increased $\mathrm{Ca}$ content in the central region of the cell is coincident with the vacuole location.Diatoms clearly responded to environmental alterations, by changing cytoplasm morphology, concentrating added metals, and altering Fe transport mechanisms. The different metal accumulation patterns indicated higher susceptibility of diatoms to $\mathrm{Cu}$, retained in cytoplasm, than to $\mathrm{Ni}$ and $\mathrm{Zn}$, mobilized to the vacuole. Metal mapping gave clues about metal transport, toxicity, and fate in the ecosystem. These aspects highlight the value of diatoms as biomonitors of environmental quality and allowed estimating consequences of metal pollution in marine biogeochemical cycles.

R.M. Godinho and T. Cabrita thanks support from "Fundação para a Ciência e a Tecnologia" through grants SFRH_BPD_47473_2008 and SFRH/BPD/50348/2009. 
[1] Twining, B.S. et al., Anal. Chem., 75, 3806-3816, 2003.

[2] Ynsa, M.D. et al., Microsc. Microanal., 18, 1060-1066, 2012.

[3] Godinho, R.M. et al., Nucl. Instrum. Meth. B, 306, 150-152, 2013.

[4] Cotté-Krief, M.H. et al., Mar. Chem., 71, 199-214, 2000.
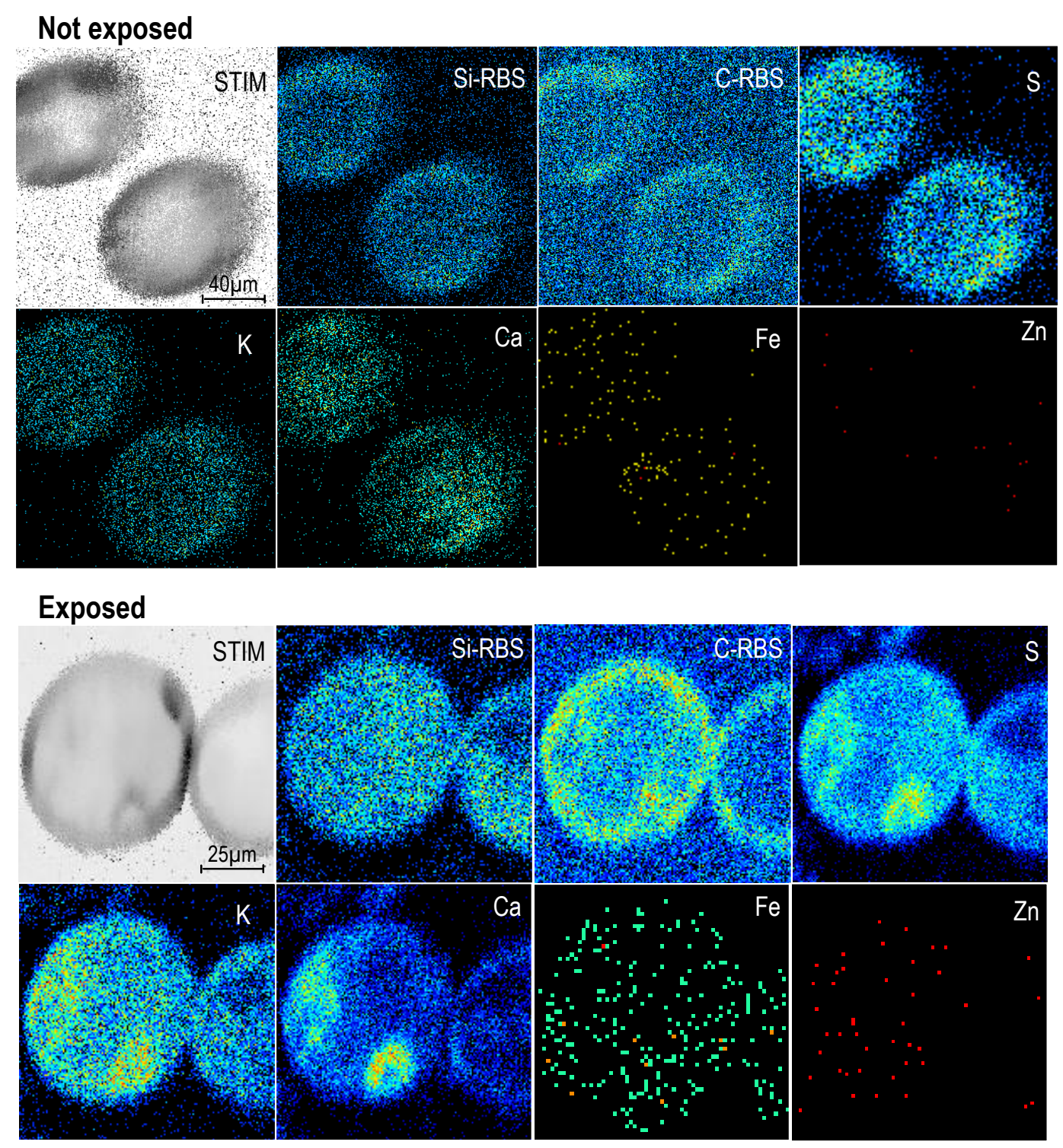

Figure 1. Mass density (STIM) and elemental distribution in individual Coscinodiscus eccentricus cells in pervalvar view. Content gradient represented by a dynamic colour scale: STIM, high density - black, to low density - white; Elements, high content - red, to low content - blue. 